\title{
The Atomic Energy Commission Library System: Its Origin and Development
}

Mr. Fry is chief librarian, Atomic Energy Commission, Washington, D.C.; $M r$. $W$ arheit is chief, and Mr. Randall assistant chief, Library Section, Technical Information Branch, Oak Ridge.

$\mathrm{T}^{\mathrm{s}}$ HE PROVISION of library service to the atomic energy program is unusual in several respects - in its scope, in its organization and in the methods of achieving dissemination within security controls. In the past three years the Atomic Energy Commission has developed a large, unique, decentralized library system which includes all of the libraries of the Atomic Energy Commission and its contractors dispersed from Long Island to Los Angeles.

The size of the system can be estimated Noy the extent of the services the units in I the system obtained from the central Oak - Ridge A.E.C. Library. In 1948 the central - library distributed 50,000 research and development reports, sent over two million catalog cards indexing reports to the 68 catalogs of the system's libraries, answered 2500 reference or information requests, and issued 50,000 copies of its three bibliographic journals.

The libraries in the Atomic Energy Commission system are not centrally controlled and administered. Each library is independent of the others and is administered by contractors at the various sites. To comprehend this decentralized system, a short résumé of the A.E.C. organization is desirable. The A.E.C. maintains its headquarters offices in Washington, D.C. Among its basic principles is that of contracting with industry and educational institutions for the operation of its production and research activities. In each area where these activities are carried on, the A.E.C. has an operations office which supervises and controls the activities of the contractors of that area. The A.E.C. in Washington and its operations offices have approximately 4500 employees, its contractors have 70,000 employees. $\mathrm{Li}$ braries are maintained by each contractor as well as by A.E.C. at Washington and Oak Ridge and certain regional offices. Those maintained by the contractor are supervised by and responsible to the line organizations of the contractor.

Some of these libraries, notably those serving the larger laboratories, Argonne, Brookhaven, Los Alamos, Oak Ridge, etc., have large, well-organized holdings in atomic energy and related fields which are being rapidly developed into great scholarly collections, unique in their areas. The typical library consists of a comprehensive collection of scientific and technical publications, plus a separate document file room for classified research and development reports. While each of these libraries is primarily interested in giving library service to its installation personnel, the service frequently exceeds this limitation. All 
libraries give and receive interlibrary loan service. Brookhaven is extensively engaged in bibliographic work which receives wide distribution. Libraries at the production plants of Oak Ridge (K-25 and Y-12) and Hanford contribute to the A.E.C. cataloging program for reports. Argonne initiated an indexing system for the plutonium project reports which was expanded by the commission to cover all A.E.C. reports.

In spite of this decentralization, the libraries, by virtue of the common interest, have formed a definite operating system. They use the same materials, draw upon the same centralized cataloging, reference and bibliographic services, and are limited in the exchange of documents to authorized project personnel.

This library system has evolved in the past three years. During the war it was necessary to protect the secret of the activities of the U. S. Army Manhattan Engineer District (the military predecessor of the A.E.C.) by the most stringent security regulations. One of the methods used was that of compartmentalization, limiting the information available to personnel to that actually required for the performance of their work. While this type of restriction made the manufacture of the atomic bomb the best kept secret in history, it inherently caused waste and unnecessary duplication of research. In the spring of 1946, the Manhattan District established a system for controlled exchange of scientific and technical information to promote wider authorized dissemination within the district and the release of certain types of information to the public. To implement this program, a declassification unit was established to review and remove the security classification from selected reports and thereby make them available to the public. At the same time a library unit was also started in the research division at Oak Ridge to facilitate the exchange of research and development reports between the various installations engaged in atomic energy work.

Within a few months the library at Oak Ridge amassed a substantial collection of reports. Because of the rigid security regulations, certain types of information on nuclear science could not be found in the open literature. Project personnel had to rely on the reports written by their co-workers in the field which explains the emphasis placed on reports by the libraries in the system. In the Oak Ridge A.E.C. Library there are now over 75,000 copies of $I 8,000$ different project research and development reports. This collection is growing at the rate of 250 to 300 report titles per month.

Originally this central library was the primary source used by a field installation library to obtain reports from other installations on subjects of interest to its patrons. In June 1947, however, a system of direct distribution of current reports was established. Although this system has been in operation over a year, the A.E.C. Library still distributes an average of 4000 reports a month while it receives approximately half that number from the automatic distribution of current reports. As a result the library uses its extra copy file heavily and reproduces reports extensively from its master file. These figures apply only to those reports whose distribution must be controlled for security reasons. The unclassified and declassified report distribution from the library has exceeded 50,000 reports in a month, but much of this distribution was to non-A.E.C. recipients. This activity of the library will be discussed later.

Originally, under the Manhattan District, the library was a part of the Oak Ridge Research Division. When the A.E.C. offices were established in Washington, a Public and Technical Information Division, composed of public information, declassification, and technical infor- 
mation staff offices, was established and the library was made a part of the Technical Information Branch. In addition to library services, the Technical Information Branch is concerned with publication activities including the editing of National Nuclear Energy Series and the operation of the printing plant. At the time of the establishment of the Washington office the Oak Ridge librarian was transferred to Washington where he serves in a staff capacity as chief librarian of the Technical Information Branch.

\section{Document Control}

The care and handling of a large volume of classified information imposes many unique problems on A.E.C. installation libraries. This has required the development of special techniques in document control. To meet essential security requirements the documents must be carefully housed and protected against theft and disclosure to persons not authorized to have access to the information. It is important to know not only what documents are held but to know from whence they came, where and when they were sent, and the authority for their distribution.

To assure that this information is available, an inventory unit of the Oak Ridge library must continuously audit the holdings and trace down any misplaced documents. Originally a multiple copy receipt recorded each document transmittal, but because many receipts were used to record mass rather than individual transmittals and many of the individual reports were frequently transmitted and additional copies made, the receipt file became bulky, cumbersome and inefficient to operate. As a first step a posting system, involving the use of $\log$ books and ledger sheets was used. Later cardineer cards were used. When the number of documents handled became very large, this manual operation became inefficient and an I.B.M. punched card system for inventorying and recording the receipt and transfer of documents was instituted.

Document control has been a frequent subject of discussion at the semiannual A.E.C. library conferences. This problem is not unique to the A.E.C. but is perhaps receiving more concentrated attention than elsewhere. A great many librarians in government and industrial organizations have also been faced with this problem of careful accounting for individual documents for security reasons. Stringent control of documents will continue to be a problem as long as the international conditions require security precautions, in accordance with terms of the Atomic Energy Act of 1946.

\section{Cataloging of Reports}

One of the most obvious needs of the installation libraries was a central cataloging system which could provide an index to the report collections in much the same way the Library of Congress provides catalog cards to the public and university libraries.

The first requirement was the establishment of a list of subject headings adequate to index all A.E.C. research and development reports. The nucleus of such a service for the plutonium project had been developed during the war at the Metallurgical Laboratory of the University of Chicago. Fussler and Schram had devised a list of subject headings and had cataloged the reports issued at that site. Although their list of subject headings was based on a relatively large collection of reports, the collection was limited in its subject scope by the interest of the Metallurgical Laboratory and was not adequate to cover all the activities of the other Manhattan District installations.

A hurried expansion of the subject headings was made late in 1946 and the Oak Ridge library began to catalog reports and 
distribute the catalog cards. In 1948 there were 68 installation catalogs, some of which exceeded 80,000 cards, all serviced by A.E.C. The first expansion of the list of subject headings left much to be desired. A complete revision would have required extensive and basic changes. On the one hand there was the obvious need for a definitive list of subject headings on atomic energy and on the other was this large number of rather extensive catalogs all of which would have to be revised and reworked. When consulted, however, the individual librarians agreed that the extensive revision of the subject headings was both desirable and necessary. The revision which utilized the competence of many subject specialists was started in the spring of 1948 , completed in December and distributed to all A.E.C. affiliated libraries. At present an unclassified version of the subject heading list is being compiled for general use and release to the public. This edition should be available soon. Until it appears it is possible to use the Declassified Documents Cumulated Index, covering the first 2023 declassified documents and the subject index of Nuclear Science Abstracts to establish subject headings for nuclear science topics.

\section{Bibliographic Services}

After the bombs were dropped, compartmentalization restrictions were relaxed in 1946 to permit wider dissemination of information within the project. As a result, reports were received at a rate which made it physically impossible to keep up with all the current information, without some of the usual bibliographic aids. A bibliographic unit was organized by the central library to meet this need in September 1946. The first three assignments were: A compilation of title lists of Manhattan District declassified reports as they were issued; a publication entitled Atomic Energy in Foreign Countries; and a semimonthly abstract journal entitled Guide to Published Research on A tomic Energy.

The title list of declassified documents evolved into Abstracts of Declassified Documents. Atomic Energy in Foreign Countries was merged in 1947 with the Guide to Published Research on Atomic Energy. In July 1948 the two were combined into $\mathrm{Nu}$ clear Science Abstracts which is published semimonthly. The bibliographic unit also provides a title list and an abstract journal covering the classified research and development reports.

Distribution and utilization of Nuclear Science Abstracts is not limited to A.E.C. affiliated libraries. It is available to the public by subscription and is sent free of charge to government document depository libraries and research institutions and agencies. In addition it is made available on an exchange basis to all learned societies, institutions and other organizations issuing scientific and technical publications. By means of the exchange program many worthwhile publications not otherwise obtainable are added to the library resources of the A.E.C. Nuclear Science Abstracts is not limited in coverage to- A.E.C. documents but abstracts and indexes all available literature of interest to personnel engaged in nuclear research. Late in 1948, the John Crerar Library was given a contract to assist in the compilation of this journal. The first volume of 12 issues indicates it will run about 1000 pages and include about 5000 abstracts per year, roughly equivalent to Physics Abstracts.

\section{Central Reference Service}

The first service which the A.E.C. Library provided was the finding of reports to fill the many requests from the scattered collections. Before the card catalog was completely organized and in the days when reports were not all formalized, a request often required an extensive search before it 
could be filled. The standard distribution of current reports has decreased the simple individual requests, , but 800 requests per month are still received by the central library for reports and technical information. While some of these are still easily answered, more and more of the requests are on a subject basis, many of them for specific information or bibliographies. The unit originally organized to find reports is now providing the central reference service required to meet these new requests for information and is often called upon to procure information which can only be obtained from scientists before it is written up in the report literature. In addition to subject requests the unit also makes extensive bibliographic searches.

\section{Public Distribution}

As the A.E.C. declassified documents were released they were made available to the public through journal publication and through the Office of Technical Services. It soon became apparent, however, that only about a third of the released material could reach the public through these channels. The requests for documents became so insistent that it was decided either to sell them through the Superintendent of Documents or, as it proved more feasible, to sell them from Oak Ridge as a sales agent for the Superintendent of Documents.

This sales activity became a part of the library function in July 1948. Since its inception the Document Sales Agency has issued I I monthly price lists which list I064 documents. This represents well over one third of the available 2500 released titles.

Reports which are to be published in the open literature are not offered for sale. At present about II,Ooo documents are sold each month. To this must be added the 40,000 monthly "official distribution" which goes to other government agencies, depository libraries and research institutions.

\section{Conclusion}

These activities of the A.E.C. Central Library have required a staff of approximately 80 , including five professional librarians, I3 subject specialists, nine subprofessionals and the remainder clerical assistants. This large staff is due in part to the enormous amount of detailed work required in the handling of classified materials. However by work simplification, on-the-job training and mechanization, efficiencies have been progressively achieved in the past year. For example, in January I 948, 8432 cards were processed and distributed per member of the cataloging and card distribution unit. By December this figure was raised to $2 \mathrm{I}, 857$ cards per employee. The maximum number of classified documents the section could handle used to be 5000 per month; now with I.B.M. equipment well over 9000 in a month have been processed without reaching capacity. This has been a fascinating and unusual experience for the librarians concerned in developing procedures and in applying library principles and techniques to new and highly specialized material. 